\title{
Remote Cerebellar Hemorrhage after Frontal Lobectomy: Zebra Sign
}

\author{
Can Yaldiz ${ }^{*}$, Volkan Murat Unal2, Omer Akar ${ }^{3}$, Onur Yaman ${ }^{4}$, Nail Ozdemir1 \\ ${ }^{1}$ Department of Neurosurgery, Sakarya Training and Research Hospital, Sakarya, Turkey \\ ${ }^{2}$ Tepecik Education and Research Hospital, Department of Neurosurger, Izmir, Turkey \\ ${ }^{3}$ Kahramanmaras State Hospital, Neurosurgery, Kahramanmaras, Turkey \\ ${ }^{4}$ TOBB University of Economics and Technology, Department of Mechanical Engineering, Ankara, Turkey \\ Email: ${ }^{*}$ drcanyaldiz@yahoo.com
}

Received 24 July 2014; revised 24 August 2014; accepted 24 September 2014

Copyright (C) 2014 by authors and Scientific Research Publishing Inc.

This work is licensed under the Creative Commons Attribution International License (CC BY).

http://creativecommons.org/licenses/by/4.0/

(c) (i) Open Access

\section{Abstract}

Remote cerebellar hemorrhages (RCHs) are rare complications of intracranial or spinal interventions. We describe a patient with an RCH that occurred after a frontal lobectomy for an intracranial tumor. A 41-year-old female patient with a headache and partial seizures underwent a right frontal lobectomy upon detection of a right frontal mass. An RCH (zebra sign) was detected on a control cranial computed tomography (CT), which was performed upon detection of frontal lobe syndrome and mild ataxia in the patient postoperatively. Although the mechanism underlying the occurrence of RCHs after intracranial procedures is not clear, they have been attributed to an imbalance between intravascular pressure and cerebrospinal fluid (CSF) due to rapid drainage of the fluid, causing bleeding in the cerebellar parenchyma. Generally, bilateral superior cerebellar injury produces parallel flat hyperdense areas known as the zebra sign on CT. The prognosis of a cerebellar hemorrhage is generally good, and it can be treated with a conservative approach. Controlled drainage of CSF during surgery and selecting an appropriate surgical position perioperatively will reduce the risk of RCHs.

\section{Keywords}

Zebra Sign, Remote Cerebellar Hemorrhage, Lobectomy

\section{Introduction}

Intracranial hemorrhages in different intracranial regions after intracranial procedures are extremely rare and

\footnotetext{
${ }^{*}$ Corresponding author.
}

How to cite this paper: Yaldiz, C., Unal, V.M., Akar, O., Yaman, O. and Ozdemir, N. (2014) Remote Cerebellar Hemorrhage after Frontal Lobectomy: Zebra Sign. Open Journal of Modern Neurosurgery, 4, 181-185. 
usually fatal. The incidence of hemorrhages after intracranial surgery is $0.2 \%-4.9 \%$ [1]-[7]. They have been blamed on the patient's head position during surgery, attacks of hypertension during the operation, and sudden discharge of cerebrospinal fluid (CSF) [1]. The so-called zebra sign is usually seen after supratentorial vascular interventions or temporal lobe resections. It is also common after routine computed tomography (CT) [1] [7][16].

We describe a patient who underwent surgery for an intracranial tumor and developed a remote cerebellar hemorrhage (RCH) in the postoperative period.

\section{Case}

A 41-year-old female patient was admitted to our outpatient clinic due to partial seizures, which had started 3 months earlier. The seizures had abrupt onset and termination, and they usually occurred at night, causing the patient to shout out. They also caused oral paralysis, tonic contractions in the upper limbs, and headaches, which had begun 8 months earlier and gradually increased. The patient's medical history was unremarkable, and a neurological examination was normal. Laboratory tests were normal, except for the presence of hypercholesterolemia. Scalp electroencephalography (EEG) was performed as anamnesis obtained from the family suggested that she was prone to epileptic seizures. The scalp EEG revealed sharp waves, indicating frontal lobe epilepsy. The patient was hospitalized due to the presence of a mass lesion in the right frontal region observed on cranial magnetic resonance imaging (MRI) and CT of the brain obtained for investigating the etiology of the new onset epileptic focus (Figure 1 and Figure 2). The patient underwent a right frontal lobectomy, with craniectomy. Frontal lobe syndrome and mild ataxia appeared after the operation. A cerebellar hemorrhage was observed on a control cranial CT (Figure 3 and Figure 4). A control CT obtained in postoperative week one showed that the hemorrhage in the posterior fossa had regressed. No pathologies were observed on a control CT obtained one month later. Although frontal lobe syndrome was present in a neurological examination, a cerebellar examination was normal. Pathology examination results revealed a malignant glial mass, and the patient was transferred to an oncology clinic.

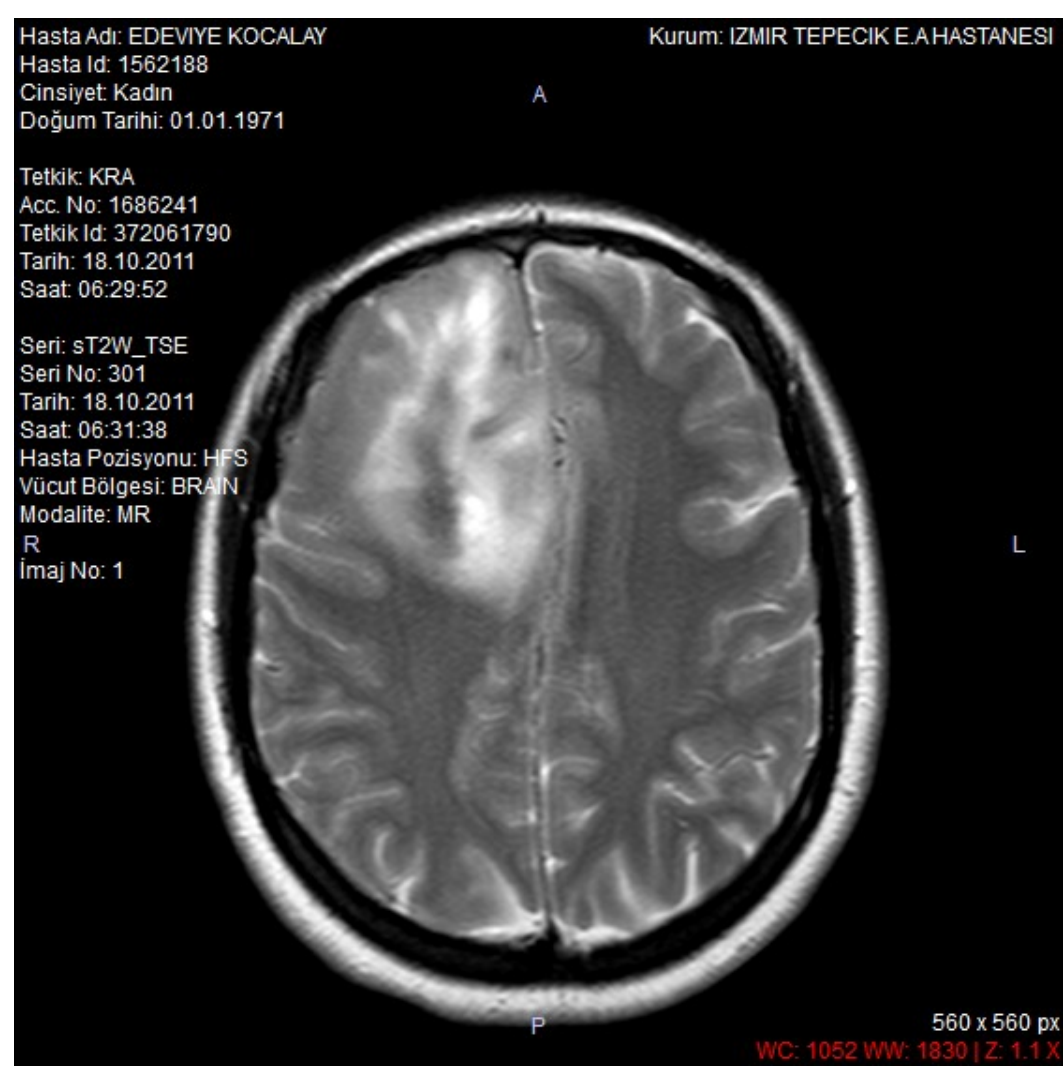

Figure 1. T2-weighted axial MRI image showing a lesion in the right frontal lobe. 


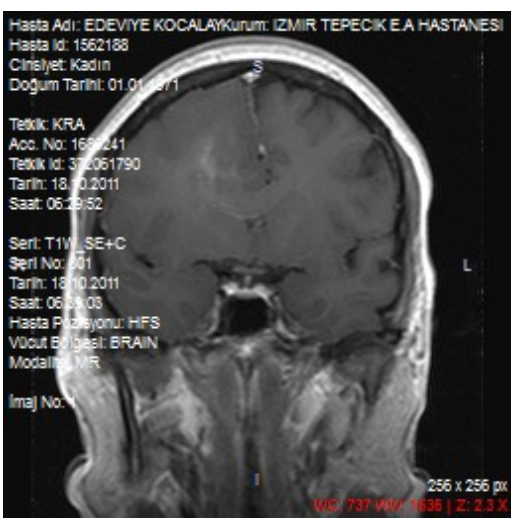

Figure 2. The right frontal mass on T1-weighted axial MRI sections.
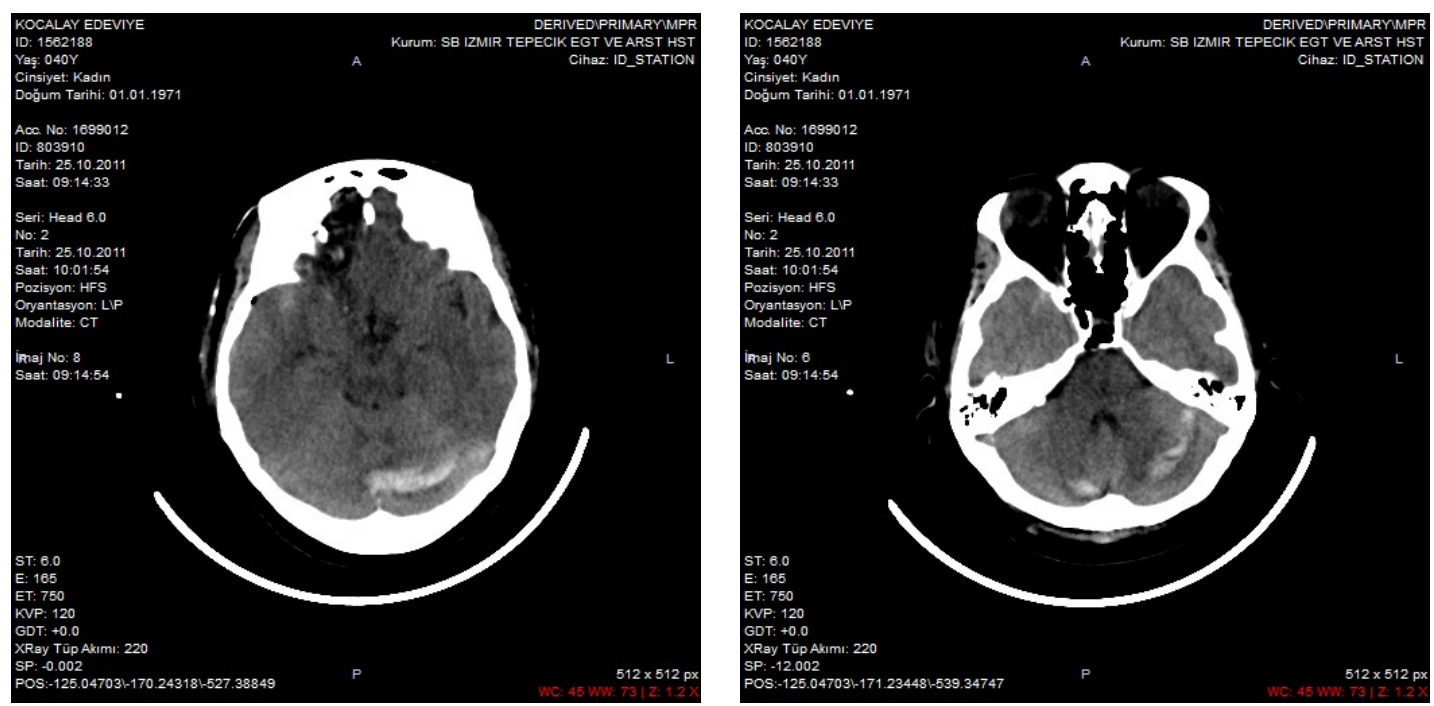

Figure 3. The axial CT sections (zebra sign) showing the RCH after the surgery.

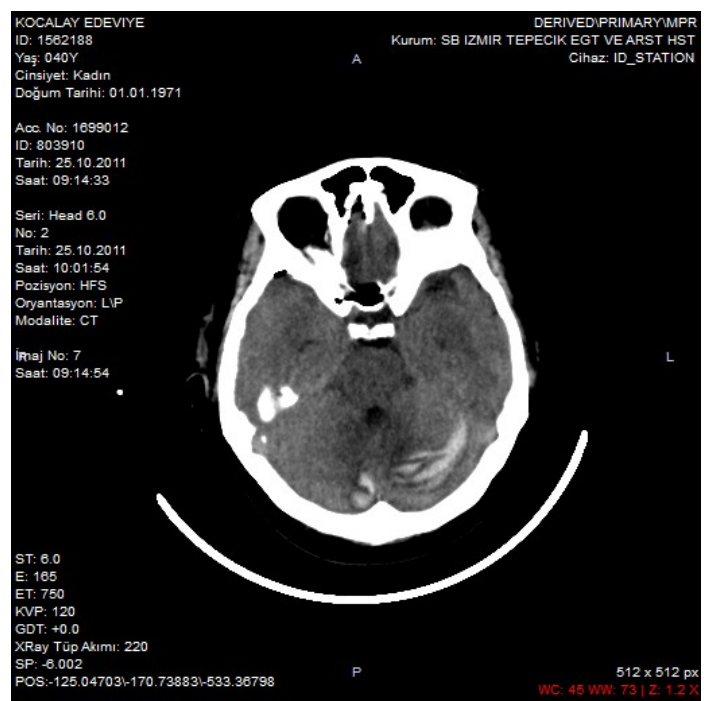

Figure 4. The axial CT sections (zebra sign) showing the RCH after the surgery. 


\section{Discussion}

After craniotomy, bleeding in the surgical field and nearby areas are common complications. However, RCHs are quite rare. RCHs are usually seen in patients aged between 30 and 60 years and are quite rare in children [16]. Chadduck et al. [5] described the first case of a cerebellar hemorrhage after spinal surgery, and Yoshida et al. [15] presented the first case of cerebral bleeding after supratentorial craniectomy.

RCHs are seen in $0.6 \%$ of cases following supratentorial interventions and $0.15 \%-4.9 \%$ of cases following temporal lobectomy surgeries [7] [10]-[14]. RCHs are mostly asymptomatic and determined on radiological imaging, which is usually done in the postoperative period [1]-[3] [7]. However, as in our case, cerebellar signs can be seen after surgery in some patients. RCHs may lead to increased intracranial pressure, as the passage to the fourth ventricle is impaired when they occur close to the midline. In such cases, interventions with external ventricular drainage systems should be used to reduce the pressure caused by increased supratentorial CSF (16). The patient's clinical condition in the present case did not require the use of an external ventricular drainage system.

The exact mechanism of RCH is not known, but several possibilities have been proposed. Antiagregan and aspirin use are possible risk factors, in addition to age, gender, transient hypertensive episodes, coagulation disorders, arterial malformations, and sinus thrombosis. However, Marquardt et al. [6] [7] showed that other than sex, the aforementioned predisposing factors were not associated with cerebellar hemorrhages. Other mechanisms implicated in RCHs are the drainage of CSF via the lamina terminalis during aneurysm surgery and the total discharge of CSF in patients following ventricular drainage. The amount of CSF loss that causes cerebellar bleeding has not been specified in the literature [1] [4] [7] [8]. The most commonly accepted opinion is that an ample amount of CSF loss after a craniotomy increases the risk of a hemorrhage [13]. In addition, no studies have compared the operative field and RCHs. We cannot fully explain the cause of the RCH in our case. However, excessive CSF discharge may be to blame.

Most theories relating to the cause of RCHs link them to venous systemic pathology. Chadduck reported that an imbalance between intravascular pressure and CSF could lead to a cerebellar parenchymal hemorrhage. Many authors have attributed the sagging of the cerebellum following spinal surgery to CSF discharge and to injury that occurred during the surgery [1] [5] [7]. Park et al. suggested that it mostly originated from the venous system, particularly the superior vermian vein, and concluded that RCHs were the result of excessive CSF discharge [17].

Bleeding usually extends to the tentorium and the neck of the vermis, at the top of the cerebellum. Characteristically, it is caused by bilateral injury of the superior cerebellar vein. RCHs mostly occur in the tentorium wall of cerebellar parenchyma and in the dentate nucleus region [17]. On CT, they show up as parallel flat hyperdense areas known as the zebra sign [7] [8]. Our case had only the zebra sign. In the series reported by Brisman et al. [9], bleeding was more frequent with the patient in a sitting position. In contrast, Kalfas et al. [10] reported that the surgical position had little effect on RCHs.

The treatment of patients with a RCH should be planned according to the severity of the cerebellar hemorrhage and the types of complications present. A cerebellar hemorrhage often has a good prognosis. Small cerebellar hemorrhages can be treated with a conservative approach and followed up with radiological methods. In $10 \%-15 \%$ of patients, severe bleeding occurs and causes mortality. In such cases, the evacuation of the hematoma, external drainage to prevent the development of hydrocephalus due to compression of the fourth ventricle, and brain stem compression may be required [1] [7].

In conclusion, a conservative approach is appropriate for a clinically stable patient with an RCH if obstructive hydrocephaly is not present. CSF pressure should be reduced with an external ventricular drainage system if there is pressure on the fourth ventricle and obstructive hydrocephaly and clinical deterioration are present. The hematoma should be evacuated with craniectomy if the brain is directly under pressure [16].

\section{Conclusion}

Although RCHs are well-defined hemorrhages, their underlying mechanisms are not clear, with no one predisposing factor know to be responsible. In common with most current opinions, we believe that they are the result of stress that develops in the veins after the drainage of CSF. We consider that slow discharge of CSF during surgery and the selection of an appropriate surgical position in the perioperative period can reduce the risk of RCHs. 


\section{References}

[1] Cemil, B., Kırar, F., Gökce, E.C., Tekşam, M. and Erdoğan, B. (2010) Supratentoryal ve Spinal Cerrahi Sonras1 Gelişen Serebellar Kanamalar: Iki Olgu Sunumu. Türk Nöroşirürji Dergisi, 20, 117-121.

[2] Amini, A., Osborn, A.G., McCall, T.D. and Couldwell, W.T. (2006) Remote Cerebellar Hemorrhage. AJNR American Journal of Neuroradiology, 27, 387-390.

[3] Bernal-García, L.M., Cabezudo-Artero, J.M., Ortega-Martínez, M., Fernández-Portales, I., Ugarriza-Echebarrieta, L.F., Pineda-Palomo, M., Porras-Estrada, L.F. and Gómez-Perals, L.F. (2008) Remote Cerebellar Hemorrhage after Lumbar Spinal Fluid Drainage. Report of Two Cases and Literature Review. Neurocirugia (Astur), 19, 440-445.

[4] Brockmann, M.A., Nowak, G., Reusche, E., Russlies, M. and Petersen, D. (2005) Zebra Sign: Cerebellar Bleeding Pattern Characteristic of Cerebrospinal Fluid Loss. Case Report. Journal of Neurosurgery, 102, 1159-1162. http://dx.doi.org/10.3171/jns.2005.102.6.1159

[5] Chadduck, W.M. (1981) Cerebellar Hemorrhage Complicating Cervical Laminectomy. Neurosurgery, 9, 185-189. http://dx.doi.org/10.1227/00006123-198108000-00016

[6] Marquardt, G., Setzer, M., Schick, U. and Seifert, V. (2002) Cerebellar Hemorrhage after Supratentorial Craniotomy. Surgical Neurology, 57, 241-251. http://dx.doi.org/10.1016/S0090-3019(02)00642-0

[7] Figueiredo, E.G., Amorim, L.O. and Teixeiria, M.J. (2009) Remote Cerebellar Hemorrhage (Zebra Sign) in Vascular Neurosurgery: Pathophysiological Insights. Neurologia Medico-Chirurgica (Tokyo), 49, 229-234. http://dx.doi.org/10.2176/nmc.49.229

[8] Cevik, B., Kirbas, I., Cakir, B., Akin, K. and Teksam, M. (2009) Remote Cerebellar Hemorrhage after Lumbar Spinal Surgery. European Journal of Radiology, 70, 7-9. http://dx.doi.org/10.1016/j.ejrad.2008.01.004

[9] Brisman, M.H., Bederson, J.B., Sen, C.N., Germano, I.M., Moore, F. and Post, K.D. (1996) Intracerebral Hemorrhage Occurring Remote from the Craniotomy Site. Neurosurgery, 39, 1114-1122. http://dx.doi.org/10.1097/00006123-199612000-00009

[10] Kalfas, I.H. and Little, J.R. (1988) Postoperative Hemorrhage: A Survey of 4992 Intracranial Procedures. Neurosurgery, 23, 343-347. http://dx.doi.org/10.1097/00006123-199612000-00009

[11] König, A., Laas, R. and Herrmann, H.D. (1987) Cerebellar Haemorrhage as a Complication after Supratentorial Craniotomy. Acta Neurochirurgica, 88, 104-108. http://dx.doi.org/10.1007/BF01404145

[12] Papanastassiou, V., Kerr, R. and Adams, C. (1996) Contralateral Cerebellar Hemorrhagic Infarction after Pterional Craniotomy: Report of Five Cases and Review of the Literature. Neurosurgery, 39, 841-852. http://dx.doi.org/10.1097/00006123-199610000-00040

[13] Toczek, M.T., Morrell, M.J., Silverberg, G.A. and Lowe, G.M. (1996) Cerebellar Hemorrhage Complicating Temporal Lobectomy: Report of Four Cases. Journal of Neurosurgery, 85, 718-722. http://dx.doi.org/10.3171/jns.1996.85.4.0718

[14] Yacubian, E.M., de Andrade, M.M., Jorge, C.L. and Valero, R.M. (1999) Cerebellar Hemorrhage after Supratentorial Surgery for Treatment of Epilepsy: Report of Three Case. Neurosurgery, 45, 159-162. http://dx.doi.org/10.1097/00006123-199907000-00036

[15] Yoshida, S., Yonekawa, Y., Yamashita, K., Ihara, I. and Morooka, Y. (1990) Cerebellar Hemorrhage after Supratentorial Craniotomy: Report of Three Cases. Neurologia Medico-Chirurgica, 30, 738-743. http://dx.doi.org/10.2176/nmc.30.738

[16] Sasani, M., Sasani, H. and Ozer, A.F. (2010) Bilateral Late Remote Cerebellar Hemorrhage as a Complication of a Lumboperitoneal Shunt Applied after Spinal Arteriovenous Malformation Surgery. Journal of Spinal Cord Medicine, 33, 77-79.

[17] Park, J.S., Hwang, J.H., Park, J., Hamm, I.S. and Park, Y.M. (2009) Remote Cerebellar Hemorrhage Complicated after Supratentorial Surgery: Retrospective Study with Review of Articles. Journal of Korean Neurosurgical Society, 46, 136-143. http://dx.doi.org/10.3340/jkns.2009.46.2.136 
Scientific Research Publishing (SCIRP) is one of the largest Open Access journal publishers. It is currently publishing more than 200 open access, online, peer-reviewed journals covering a wide range of academic disciplines. SCIRP serves the worldwide academic communities and contributes to the progress and application of science with its publication.

Other selected journals from SCIRP are listed as below. Submit your manuscript to us via either submit@scirp.org or Online Submission Portal.
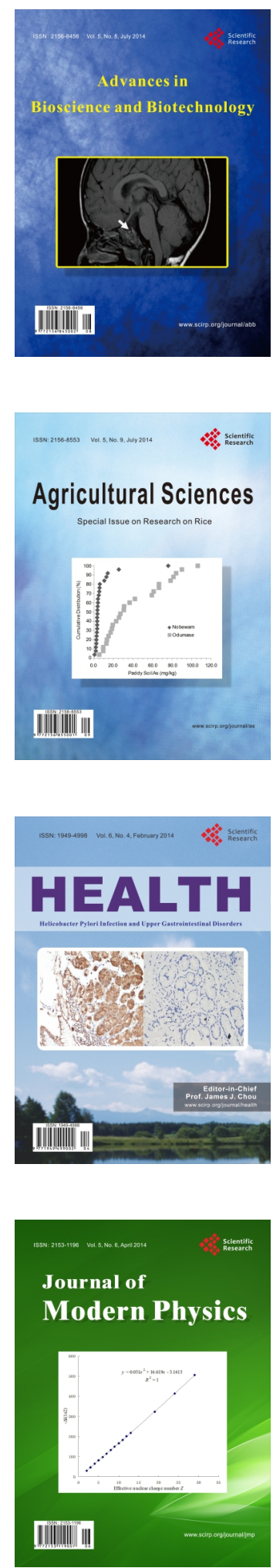
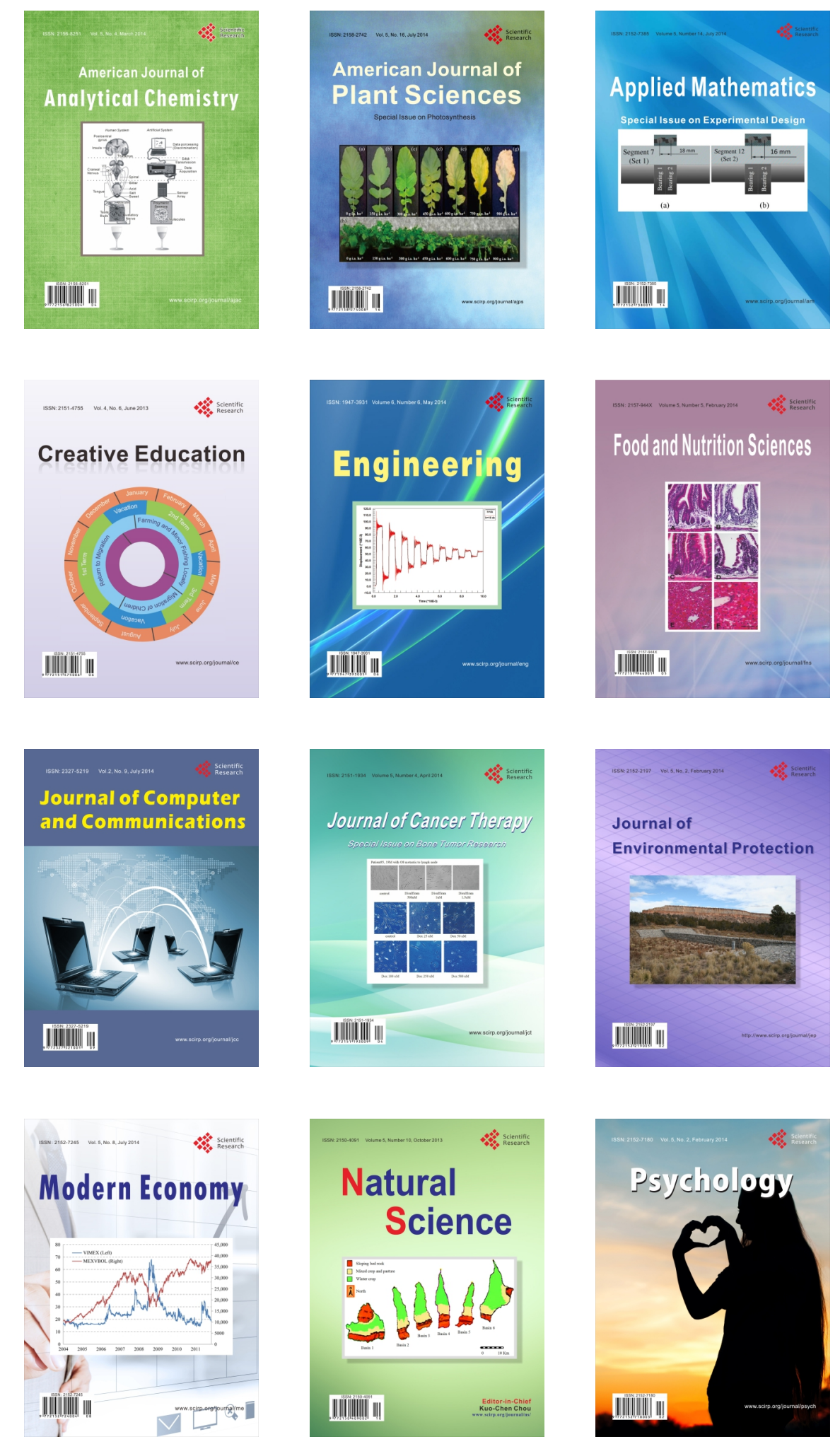